\title{
Infective endocarditis after mitral valve repair wherefore mitral valve replacement was performed
}

\author{
(D) Vera Slatinski', \\ (D)Ante Pašalićc*, \\ (D)Marko Perčić', \\ (D)Zrinka Planinić', \\ (D)Edvard Galić ${ }^{1,2}$ \\ "University Hospital "Sveti \\ Duh", Zagreb, Croatia \\ 2University of Zagreb School \\ of Medicine, Zagreb, Croatia
}

KEYWORDS: mitral valve repair, mitral valve replacement, infective endocarditis CITATION: Cardiol Croat. 2018;13(5-6):189. | https://doi.org/10.15836/ccar2018.189

*ADDRESS FOR CORRESPONDENCE: Ante Pašalić, Klinička bolnica "Sveti Duh“, Sv. Duh 64, HR-10000 Zagreb, Croatia. / Phone: +385-91-3712-083 / E-mail: ante.pasalic@outlook.com

ORCID: Vera Slatinski, https://orcid.org/0000-0002-8590-7589 • Ante Pašalić, https://orcid.org/0000-0001-5989-6495 Marko Perčić, https://orcid.org/0000-0001-7904-8899 • Zrinka Planinić, https://orcid.org/0000-0001-8664-3338 Edvard Galić, https://orcid.org/0000-0002-5707-0961

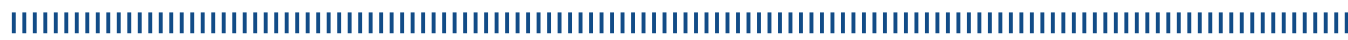

Background: Mitral valve prolapse (MVP) is a common disorder, affecting 2-3\% of general population, characterized by myxomatous degeneration of mitral valve cusps ${ }^{1}$. It is a progressive disease which may lead to severe mitral regurgitation (MR), increase in the mitral annular diameter, left atrial enlargement, atrial fibrillation, thromboembolic events, left ventricular dysfunction, heart failure and sudden cardiac death ${ }^{1}$. Therapeutic modalities for treating severe MR include mitral valve repair and replacement ${ }^{2}$. Following surgical treatment possible complications include infective endocarditis, sepsis, thromboembolic events, hemorrhage, artificial valve failure, pericardiotomy syndrome etc. Mitral valve repair, when compared to mitral valve replacement, shows lower mortality rate, therefore guidelines recommend it as the method of treatment. It is also important to notice that mitral valve repair shows lower rate of infective endocarditis ${ }^{3}$

Case report: In this article we present a case of young woman who had mitral valve prolapse with severe symptomatic MR. After mitral valve repair was performed, patient developed Staphylococcus epidermidis endocarditis (and consequential sepsis), which was verified via transthoracic and transesophageal echocardiography. After developing anaphylactic reaction to vancomycin and DRESS syndrome on teicoplanin and rifampicin, antibiotic therapy was changed to fosfomycin and ciprofloxacin. Additionally, postcardiotomy syndrome was present. Control echocardiography showed a loose, flotation mass with a thin pedicle, connected to the basis of anterior mitral cusp, on the atrial side, $12 \times 8 \mathrm{~mm}$ in diameter. Due to its high embolic potential, in consultation with cardiac surgeon, mitral valve replacement was done, and mechanical artificial mitral valve was implanted. Following the procedure, patient fully recovered.

Conclusion: MVP is progressive disease which can result in severe MR requiring surgical treatment. As mitral valve repair shows lower mortality rate in this case it was surgical treatment of choice. Unfortunately, our patient developed infective endocarditis, sepsis and postcardiotomy syndrome, which required prolonged hospitalization. Complex antibiotic therapy led to clinical recovery, but because of floating mass with high embolic potential, we opted for reoperation.
RECEIVED:

May 1, 2018

ACCEPTED:

May 10, 2018

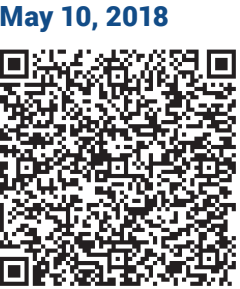

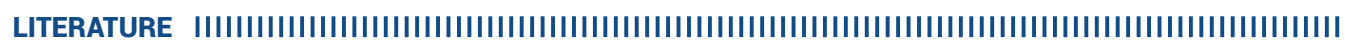

1. Delling FN, Vasan RS. Epidemiology and pathophysiology of mitral valve prolapse: new insights into disease progression, genetics, and molecular basis. Circulation. 2014 May 27:129(21):2158-70. https://doi.org/10.1161/CIRCULATIONAHA.113.006702

2. Mick SL, Keshavamurthy S, Gillinov AM. Mitral valve repair versus replacement. Ann Cardiothorac Surg. 2015 May;4(3):230-7. https://doi.org/10.3978/j.issn.2225-319X.2015.03.01

3. Thourani VH, Weintraub WS, Guyton RA, Jones EL, Williams WH, Elkabbani S, Craver JM. Outcomes and long-term survival for patients undergoing mitral valve repair versus replacement: effect of age and concomitant coronary artery bypass grafting. Circulation. 2003 Jul 22;108(3):298 304. https://doi.org/10.1161/01.CIR.0000079169.15862.13 